\title{
Challenging Presentations of Seven Cases of Gastrointestinal Basidiobolomycosis in Sudan: Clinical Features, Histology, Imaging, and Recommendations
}

\author{
Sawsan A. Mohammed ${ }^{1}$ Azza A. Abdelsatir ${ }^{2} \quad$ Mohamed Abdellatif $^{3}$ Suliman Hussein Suliman ${ }^{4}$ \\ Omer Mohammed Ibrahim Elbasheer ${ }^{5}$ Awad Rhmattalla Abdalla ${ }^{4}$ Abubakr H. Widattalla ${ }^{4}$ \\ Safeya Ahmed M. Tamimeldar ${ }^{6} \quad$ Abdelgadir A. Amin ${ }^{7} \quad$ Mohamed H. Ahmed ${ }^{8}$ \\ Ali Mohammed Abdelsatir ${ }^{2}$
}

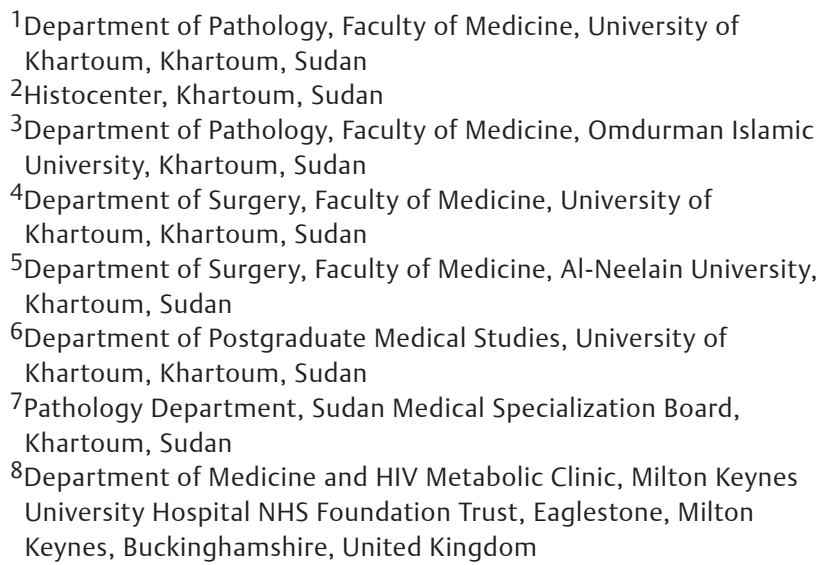

Address for correspondence Sawsan A. Mohammed, MBBS, MD, Department of Pathology, Faculty of Medicine, University of Khartoum, Al-Gamaa Avenue, Khartoum 11111, Sudan (e-mail: sawsanaa2003@yahoo.com).

J Lab Physicians:2020;12:281-284
Abstracts
Keywords
- basidiobolomycosis
- gastrointestinal
- Sudan

\begin{abstract}
Basidiobolomycosis is a fungal infection caused by Basidiobolus ranarum which affects the skin and subcutaneous tissue and rarely the gastrointestinal tract. We report seven cases of gastrointestinal basidiobolomycosis with interesting clinical, radiological, and histological presentations. To our knowledge, this is the first case series of abdominal basidiobolomycosis to be reported from Sudan.
\end{abstract}

\section{Introduction and Summary of Cases}

Gastrointestinal infection with basidiobolomycosis is due to ingestion of contaminated food. ${ }^{1}$ The most common presenting feature is vague abdominal pain sometimes associated with diarrhea or constipation. ${ }^{2}$ Most patients are usually immunocompetent and they present with features of acute appendicitis or features of intestinal obstruction mimicking cancer. $^{3-8}$ The diagnosis is based on histological examination of a deep biopsy from the affected site. The treatment is a combination of antifungal drugs and surgery., ${ }^{3,4}$ All our patients, except for the patient with features of acute appendicitis, underwent resection surgery due to suspicion of a mass. Therefore, cultures were not obtained as the surgical

DOI https://doi.org/

$10.1055 / \mathrm{s}-0040-1721149$

ISSN 0974-2727. teams' initial diagnosis was malignancy and all specimens were received fixed in $10 \%$ buffered formalin. The seven samples of the cases were obtained from the period of December 2017 and December 2018 (five specimens were sent to Khartoum Histocenter and two specimens to Khartoum Soba University Hospital Laboratory). From the paraffin-embedded blocks, hematoxylin and eosin stained sections were done and examined under light microscope. Periodic acidSchiff and Grocott silver stains were used to highlight the fungal hyphae and zygospores. ${ }^{5}$ Among the seven patients, three were children, presented with abdominal mass, rectal bleeding, and features of acute appendicitis. The remaining four patients were adults three of them were males and one female, two presented with abdominal pain, one with a

(C)2020. The Indian Association of Laboratory Physicians.

This is an open access article published by Thieme under the terms of the Creative Commons Attribution-NonDerivative-NonCommercial-License, permitting copying and reproduction so long as the original work is given appropriate credit. Contents may not be used for commercial purposes, or adapted, remixed, transformed or built upon. (https://creativecommons.org/licenses/by-nc-nd/4.0/). Thieme Medical and Scientific Publishers Pvt. Ltd. A-12, 2nd Floor, Sector 2, Noida-201301 UP, India 
stenotic mass at the ileocecal junction, and two were known to have diabetes. Radiology revealed mural thickening of the bowel wall with stenosis. All patients underwent surgery due to suspicion of malignancy except for the child who presented with symptoms of acute appendicitis. The bowel specimens were characterized by marked thickening of the wall with fibrosis. Histologic examination showed transmural prominent tissue eosinophil infiltration and granulomatous inflammation around pale fungal hyphae extending to the mesenteric fat sparing the mucosa. Importantly, the seven patients received antifungal treatment and five of them recovered except two adult males died. Two patients in this case series received itraconazole for the first 2 months with no clinical improvement and showed better response to voriconazole. The clinical, laboratory, and surgical features of all patients are presented in - Table $\mathbf{1}$. All patients have signed the written consent for publication.

\section{Case 1}

A 53-year-old male from Al-Jazeera state (central of Sudan) known to have diabetes and hypertension, presented complaining of abdominal pain and right lower quadrant swelling for 1 month. Ten days before hospital admission, he was diagnosed as a case of appendicular mass and treated conservatively. Abdominal examination showed mildly distended abdomen with a visible mass in the right iliac fossa. Computed tomography (CT) abdomen showed diffuse circumferential wall thickening of the cecum with surrounding fat stranding, mild ascites, but no para-aortic lymph nodes enlargement. This was thought to be highly suggestive of cecal malignant tumor with subacute bowel obstruction. Therefore, he was treated surgically (right hemicolectomy) without blood culture, colonoscopy, and biopsy. During surgery he was found to have cecal mass measuring $8 \times 7 \mathrm{~cm}$ fixed to the posterior abdominal wall. Importantly, histopathology result showed basidiobolomycosis and he was immediately started on antifungal treatment (voriconazole). He developed pulmonary edema and died.

\section{Case 2}

A 17-year-old female presented with vague abdominal pain. Clinical examination revealed an abdominal mass. CT scan showed multifocal omental thickening and thick wall bowel loops. The working diagnosis was lymphoma/abdominal tuberculosis (TB). Omental biopsy was taken and showed basidiobolomycosis. The patient was referred for surgical excision of mass. Transverse colon with adherent omentum was resected. Cut surface of colon shows circumferential thickening of the wall and serosa with homogenous white appearance. Histopathology showed circumferential inflammatory mass composed of mixed inflammatory infiltrate composed of eosinophils, neutrophils, and multinucleated giant cells surrounding broad fungal hyphae and zygospores. She was successfully treated with voriconazole as she did not show improvement with itraconazole.

\section{Case 3}

A 13-year-old male presented with relative constipation, bleeding per rectum for 1 week. Examination revealed a 4-cm rectal mass. Rectal biopsy showed basidiobolomycosis. He was commenced on itraconazole and then switched to voriconazole. Limited rectal resection and resected colon showed stenosis and thickening of bowel wall. He was successfully treated with prolong course of voriconazole.

\section{Case 4}

A 56-year-old female known to have diabetes initially diagnosed as intra-abdominal sepsis. She underwent exploratory laparotomy which revealed perforated appendix and a mass at the base of the cecum with perforation and enlarged mesenteric lymph nodes. Therefore, she underwent appendectomy and right hemicolectomy. Grossly inspection showed

Table 1 Clinicopathologic features of patients with gastrointestinal basidiobolomycosis

\begin{tabular}{|l|l|l|l|l|l|l|l|l|l|l|}
\hline Case & $\begin{array}{l}\text { Age } \\
(\mathbf{y})\end{array}$ & Sex & Symptoms & $\begin{array}{l}\text { WBC } \\
\times 10 / \mathbf{m m}^{3}\end{array}$ & $\begin{array}{l}\text { Eosinophils } \\
\%\end{array}$ & $\begin{array}{l}\text { ESR } \\
\mathbf{m m} / \mathbf{h}\end{array}$ & $\begin{array}{l}\text { Radiological } \\
\text { findings }\end{array}$ & $\begin{array}{l}\text { Clinical } \\
\text { diagnosis }\end{array}$ & Treatment \\
\hline 1 & 53 & M & $\begin{array}{l}\text { Abdominal } \\
\text { pain }\end{array}$ & 16.4 & Not done & 90 & Cecal mass & $\begin{array}{l}\text { Colonic } \\
\text { carcinoma }\end{array}$ & $\begin{array}{l}\text { Right hemicolectomy } \\
+ \text { voriconazole orally }\end{array}$ & Died \\
\hline 2 & 17 & F & $\begin{array}{l}\text { Abdominal } \\
\text { mass }\end{array}$ & NA & NA & NA & $\begin{array}{l}\text { Thick large } \\
\text { bowel wall }\end{array}$ & Lymphoma & $\begin{array}{l}\text { Transverse colectomy } \\
+ \text { voriconazole orally }\end{array}$ & Well \\
\hline 3 & 13 & M & $\begin{array}{l}\text { Constipation } \\
\text { and bleeding } \\
\text { per rectum }\end{array}$ & NA & NA & NA & Rectal mass & $\begin{array}{l}\text { Limited rectal } \\
\text { resection }\end{array}$ & Well \\
\hline 4 & 56 & F & $\begin{array}{l}\text { Abdominal } \\
\text { pain and } \\
\text { fever }\end{array}$ & NA & NA & NA & $\begin{array}{l}\text { Perforated } \\
\text { appendix and } \\
\text { cecal mass }\end{array}$ & $\begin{array}{l}\text { Colonic } \\
\text { carcinoma }\end{array}$ & $\begin{array}{l}\text { Right hemicolectomy } \\
+ \text { voriconazole }\end{array}$ & Died \\
\hline 5 & 58 & M & $\begin{array}{l}\text { Intestinal } \\
\text { obstruction }\end{array}$ & NA & NA & NA & Sigmoid mass & $\begin{array}{l}\text { Colonic } \\
\text { carcinoma }\end{array}$ & Sigmoid colectomy & Well \\
\hline 6 & 50 & M & $\begin{array}{l}\text { Abdominal } \\
\text { pain }\end{array}$ & NA & NA & NA & Cecal mass & $\begin{array}{l}\text { Colonic } \\
\text { carcinoma }\end{array}$ & Right hemicolectomy & Well \\
\hline 7 & 6 & F & $\begin{array}{l}\text { Right iliac } \\
\text { fossa mass }\end{array}$ & 17.91 & 1 & 30 & $\begin{array}{l}\text { Thickening } \\
\text { of transverse } \\
\text { colon wall }\end{array}$ & $\begin{array}{l}\text { Appendicitis } \\
\text { Appendectomy + } \\
\text { voriconazole }\end{array}$ & Well \\
\hline
\end{tabular}

Abbreviations: ESR, erythrocyte sedimentation rate; F, female; M, male; NA, not available; WBC, white blood cell. 
thickened wall of the cecum. Histopathology showed surface ulceration and transmural inflammation of appendix and presence of fungal hyphae surrounded by mixed infiltration of neutrophils and granulomatous inflammation with marked infiltration of eosinophils. The ileocecal valve and omentum were also involved. She was commenced on voriconazole, but sadly the patient did not survive.

\section{Case 5}

A 58-year-old male presented with symptoms of intestinal obstruction. Colonoscopy showed sigmoid mass and biopsy showed granuloma of schistosomiasis. Laparotomy showed a tumor involving the sigmoid, descending and part of the transverse colon, cecum, and terminal ileum, and this was treated with right hemicolectomy. Cut surface of colon showed white tumor involving the ileocecal junction with ulceration of the mucosa and presence of basidiobolomycosis. The patient recovered well.

\section{Case 6}

A 50-year-old male presented with cecal mass. Working diagnosis was malignant neoplasm, so right hemicolectomy was performed with ileotransverse anastomosis. The cut surface of the cecum showed diffuse wall thickening with focal area of necrosis and presence of basidiobolomycosis and made full recovery.

\section{Case 7}

A 6-year-old female presented with right iliac fossa pain. Appendectomy was performed as initial diagnosis was acute appendicitis. Appendix measuring $3.5 \times 2 \times 1 \mathrm{~cm}$ cut surface show thickened wall. Histology of appendix showed transmural eosinophil and giant cell inflammatory infiltrate extending into periappendiceal adipose tissue. Patient was offered right hemicolectomy as she showed no response to antifungal treatment.

\section{Discussion}

Basidiobolomycosis is a fungal infection caused by Basidiobolus ranarum. It belongs to the class Zygomycetes. The Zygomycetes includes two fungal orders: Mucorales and Entomophthorales. The Mucorales cause infection in immunocompromised patients and include Mucor species and Entomophthorales which affect immunocompetent individuals and include $B$. ranarum. ${ }^{4,5}$ Basidiobolus species is a fungus found in soil and decaying vegetables and also in the intestines of some animals like fish and is endemic in tropical parts of Asia and Africa. ${ }^{6-14}$ It is well known to cause subcutaneous involvement and it may leads to subcutaneous nodules, lymphedema, and hyperpigmentation in the extremities, buttocks, and back. ${ }^{4}$ Most subcutaneous cases are contracted through minor trauma to the skin or a bite of an insect. ${ }^{10}$ The first case of subcutaneous mycosis caused by B. ranarum was reported in 1956 in Indonesia. ${ }^{4}$ In addition, a few orbitofacial cases has been reported..$^{15}$

Infection of the gastrointestinal tract is rare and is mostly acquired by ingestion of contaminated food, the organism being a vegetable saprophyte. To date, less than 80 cases have been reported worldwide in both children and adult. Most of the cases were reported from Saudi Arabia, United States, and Iran. ${ }^{4}$ The first case reported as gastrointestinal basidiobolomycosis was in 1964 in a 6-year-old Nigerian boy.

It can affect any part of the gastrointestinal tract including the stomach, duodenum, pancreas, liver, terminal ileum, cecum, ascending colon, transverse colon, rectum, and biliary system. The site of involvement in most of our cases occurred at the ileocecal junction. ${ }^{4}$

Gastrointestinal basidiobolomycosis affects males more than females and can affect adults and children. ${ }^{5}$ The clinical presenting features are nonspecific. Abdominal pain and fever are most common presenting features. ${ }^{6}$ Other symptoms reported in the literature include constipation, rectal bleeding, abdominal distension, intestinal obstruction, fever, sweats, diarrhea, memory loss, and rectal pain. ${ }^{1,4}$ Complete blood count usually shows leukocytosis, striking eosinophilia, and high erythrocyte sedimentation rate. ${ }^{1}$ Owing to the vague complaints, the provisional diagnosis included inflammatory bowel disease, TB, malignancy, and appendicitis or appendicular mass. ${ }^{15}$ Ultrasound and CT scan showed colonic mass $^{7,9,10}$ ( - Figs. 1 and 2 ). Most cases underwent endoscopic biopsies none of which reached the correct diagnosis. ${ }^{5}$ The diagnosis is made by histologic examination of the resected bowel ( - Figs. 3 and 4 ) ${ }^{1,13}$ Definitive diagnosis is by isolating the organism by inoculation of fresh surgical specimen on Sabouraud agar. Specific serologic immunodiffusion tests are also available.,.,9 Polymerase chain reaction has been used recently to diagnose gastrointestinal basidiobolomycosis and it showed high sensitivity and specificity but still not widely used due to the rarity of the disease. ${ }^{4}$ Resected intestinal specimens are characterized by marked mural thickening with fibrosis ${ }^{13}$ (-Fig. 2).

On histopathologic examination, the characteristic morphologic features were transmural inflammatory infiltrate with peritoneal involvement sparing the mucosa consisting of granulomatous inflammation around fungal hyphae.

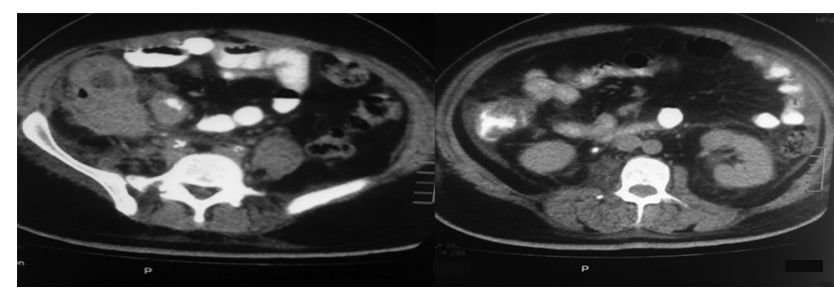

Fig. 1 Computed tomography (CT) abdomen shows diffuse circumferential wall thickening of the right (RT) colon and cecum with surrounding fat stranding.

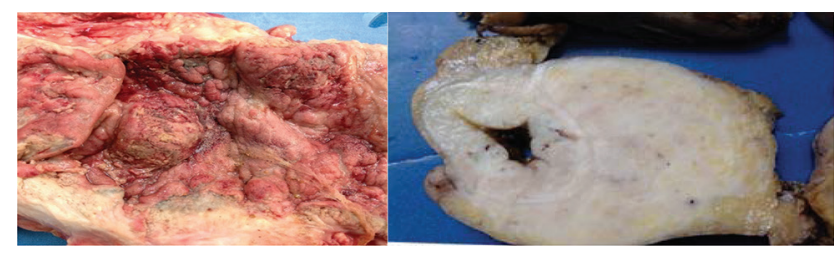

Fig. 2 Gross morphology showed thick bowel wall with stenotic mass. 


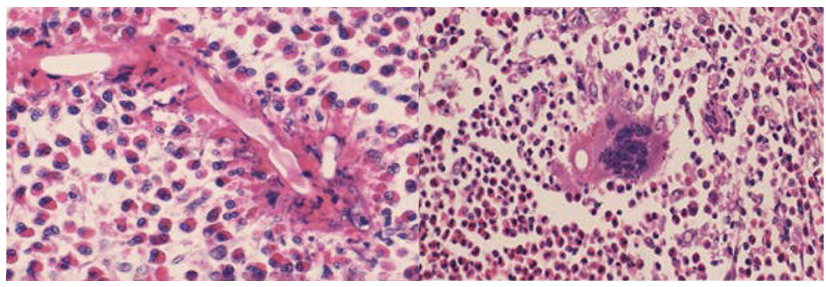

Fig. 3 Histology of the resected bowel shows broad fungal hyphae surrounded by marked eosinophil infiltrate and giant cells. SplendoreHoeppli reaction is noted. Hematoxylin and eosin (H\&E) $\times 40$.

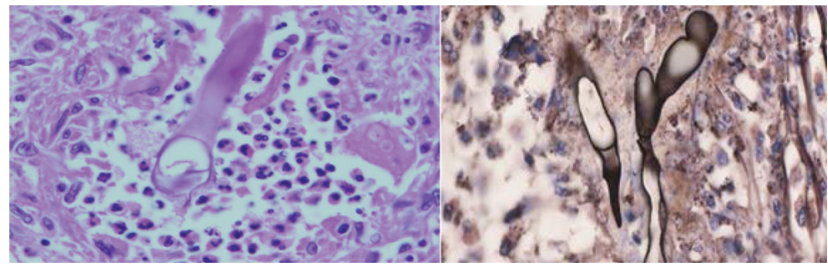

Fig. 4 Left: Periodic acid-Schiff (PAS) stain. Right: Grocott-Gomori's Methenamine Silver (GMS) stain both highlight the broad fungal hyphae.

The inflammatory infiltrate mostly consists of eosinophils, microabscesses, and giant cells. The fungal hyphae are irregular and thin walled, sometimes aggregated zygospores are seen. Splendore-Hoeppli phenomena are sometimes noted around fungal hyphae ${ }^{2,15}$ ( - Figs. 3 and $\mathbf{4}$ ). Combined surgery of the affected bowel and antifungal treatment for at least 6 months is recommended and gives better results than drugs alone. ${ }^{6,11,15}$ Itraconazole and voriconazole are the most common antifungal agents used. ${ }^{1}$ Potassium iodide has been used successfully for treatment of subcutaneous basidiobolomycosis but not gastrointestinal basidiobolomycosis. ${ }^{10}$ Basidiobolomycosis has a good prognosis. ${ }^{11}$

\section{Conclusion}

Gastrointestinal basidiobolomycosis is a rare fungal infection that affects both adults and children with male predominance. The most common presenting features were abdominal pain. Patients were operated on for suspicion of malignancy. Diagnosis can be challenging due to the nonspecific clinical presenting features; in addition, superficial intestinal mucosal biopsies can show nonspecific chronic inflammation. A combination of surgery and antifungal drugs is the treatment of choice. The prognosis is generally good. ${ }^{2}$

\section{Conflict of Interest}

None declared.

\section{References}

1 Al-Qahtani SM, Alsuheel AM, Shati AA, et al. Case reports: gastrointestinal basidiobolomycosis in children. Curr Pediatr Res 2013;17(1):1-6

2 Vikram HR, Smilack JD, Leighton JA. Crowell MD, De Petris G. Emergence of gastrointestinal basidiobolomycosis in the United States, with a review of worldwide cases. Clin Infect Dis 2012;54(12):1685-1691

3 Al Asmi MM, Faqeehi HY, Alshahrani DA, Al-Hussaini AA. A case of pediatric gastrointestinal basidiobolomycosis mimicking Crohn's disease. A review of pediatric literature. Saudi Med J 2013;34(10):1068-1072

4 Almoosa Z, Alsuhaibani M, Al Dandan S, Alshahrani D. Pediatric gastrointestinal basidiobolomycosis mimicking malignancy. Med Mycol Case Rep 2017;18:31-33

5 Geramizadeh B, Heidari M, Shekarkhar G. Gastrointestinal basidiobolomycosis, a rare and under-diagnosed fungal infection in immunocompetent hosts: a review article. Iran J Med Sci 2015;40(2):90-97

6 Sackey A, Ghartey N, Gyasi R. Subcutaneous basidiobolomycosis: a case report. Ghana Med J 2017;51(1):43-46

7 Al-Naemi AQ Khan LA, Al-Naemi I, et al. A case report of gastrointestinal basidiobolomycosis treated with voriconazole: a rare emerging entity. Medicine (Baltimore) 2015;94(35):e1430

8 Zabolinejad N, Naseri A, Davoudi Y, Joudi M, Aelami MH. Case report colonic basidiobolomycosis in a child: report of a culture-proven case. Int J Infect Dis 2014;22(May) :41-43

9 Kurteva E, Bamford A, Cross K, et al.Colonic basidiobolomycosisan unusual presentation of eosinophilic intestinal inflammation. Front Pediatr. 2020;8:142

10 Nemenqani D, Yaqoob N, Khoja H. Al Saif O, Amra NK, Amr SS. Gastrointestinal basidiobolomycosis: an unusual fungal infection mimicking colon cancer. Arch Pathol Lab Med 2009;133(12):1938-1942

11 Al-Juaid A, Al-Rezqi A, Almansouri W, Maghrabi H, Satti M. Pediatric gastrointestinal basidiobolomycosis: case report and review of literature. Saudi J Med Med Sci 2017;5(2):167-171

12 Pasha T, Leighton J, Smilack J, Komatsu K, Kioski C; Centers for Disease Control and Prevention (CDC). Gastrointestinal basidiobolomycosis-Arizona, 1994-1999. MMWR Morb Mortal Wkly Rep1999: 48(32):710, - -713

13 Rabie ME, El Hakeem I, Al-Shraim M, Al Skini MS, Jamil S. Basidiobolomycosis of the colon masquerading as stenotic colon cancer. Case Rep Surg 2011;2011:685460

14 Singh R, Xess I, Ramavat AS, Arora R. Basidiobolomycosis: a rare case report. Indian J Med Microbiol 2008;26(3):265-267

15 Bigliazzi C, Poletti V, Dell'Amore D, Saragoni L, Colby TV. Disseminated basidiobolomycosis in an immunocompetent woman. J Clin Microbiol 2004;42(3):1367-1369

\section{Funding}

None declared. 